\title{
ThE APPLiCATION OF INTERVAL COMPUTATION ON NON-LINEAR STATE ESTIMATION
}

\author{
ZBRANEK, P. \& VESELY, L.
}

Abstract: This paper present using interval analysis on nonlinear state estimation, in this concretely case of Permanent Magnet Synchronous Machine. In modern control theory, the mere knowledge of input and output parameters is not sufficient for system control. Modern control algorithms utilize current values of state variables of controlled system. These state variables are very often hardly measurable technically and financially consumptive. In this case the state estimation is used. PMSM drives offers in comparison to other drives several advantages but it is necessary to have knowledge of actual rotor position and actual speed of rotation for precise control. These data are usually obtained by state reconstructors, in most cases by extended Kalman filter or his modifications. Unfortunately, in many cases this is insufficient. That is why other methods of state estimation are researched. One of these methods is interval analysis in which results are not points, but guaranteed intervals.

Key words: nonlinear state estimation, interval analysis
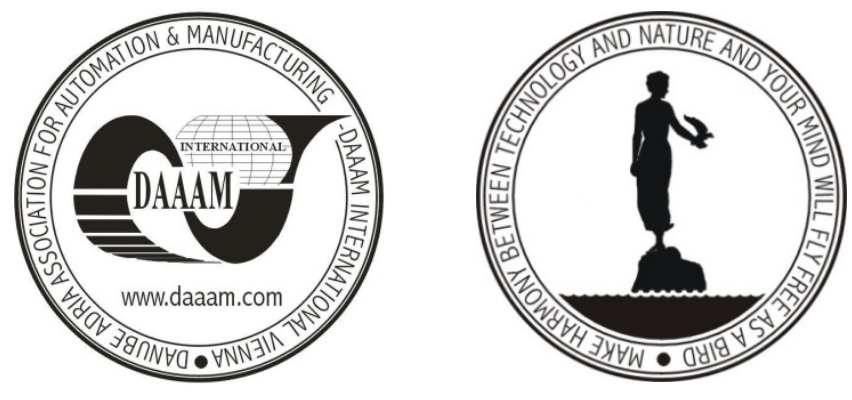

Authors' data: Ing. Zbranek, P[avel]; Ing. Vesely, L[ibor], Brno University of Technology, Udolni 244/63, 60200, Brno, Czech Republic, zbranek@feec.vutbr.cz, veselyl@feec.vutbr.cz

This Publication has to be referred as: Zbranek, P[avel] \& Vesely, L[ibor] (2009). The Application of Inteval Computation on Non-Linear State Estimation, Chapter 69 in DAAAM International Scientific Book 2009, pp. 713-720, B. Katalinic (Ed.), Published by DAAAM International, ISBN 978-3-901509-69-8, ISSN 1726-9687, Vienna, Austria

DOI: $10.2507 /$ daaam.scibook.2009.69 